\title{
Original Research \\ Comparison of chronic systolic heart failure guideline adherence for two ambulatory clinics
}

\author{
Sarah B. DEHONEY, Lori M. DICKERSON, Jean M. NAPPI. \\ Received (first version): 8-Oct-2009 \\ Accepted: 17-Jan-2010
}

\begin{abstract}
${ }^{*}$
Guidelines have been published for management of chronic systolic heart failure to reduce patient morbidity and mortality.

Objective: A quality review of the heart failure medical therapy for a community family medicine residency program clinic and a multidisciplinary heart failure specialty clinic was performed to compare adherence to ACC/AHA heart failure guidelines, with regard to medications and in titrating to recommended target doses. Methods: The study was a retrospective chart review and data collected included name and dose of any ACEI, beta-blocker, ARB, or other medication addressed in the guidelines.

Results: Specialty clinic patients had significantly lower systolic blood pressures and ejection fractions. Significantly more patients were prescribed beta-blockers in the specialty clinic population (98\% vs $80 \%, p<0.05)$. Both patient populations had very low rates of reaching target beta-blocker doses (15\% vs $21 \%, p=0.27)$. More patients in the family medicine clinic reached target doses of ACEI $(64 \%$ vs $49 \%, p<0.05)$ and ARBs $(67 \%$ vs $35 \%, p<0.05)$.

Conclusions: This study revealed the vast majority of patients in either a community family medicine residency program or heart failure specialty clinic were prescribed ACEI or ARB, and beta-blockers. However, achieving target doses should continue to be an important goal for practitioners.
\end{abstract}

Keywords: Heart Failure, Systolic. Drug Therapy. Guideline Adherence. United States.

\author{
COMPARACIÓN DEL CUMPLIMIENTO DE \\ LAS GUÍAS PARA FALLO CARDÍACO \\ CRÓNICO SISTÓLICO EN DOS CLÍNICAS \\ AMBULATORIAS
}

\section{RESUMEN}

Se han publicado guías para el manejo del fallo cardiaco sistólico crónico para reducir la morbilidad y mortalidad de los pacientes. Objetivo: Se realizó una revisión de la calidad del tratamiento del fallo cardíaco en un programa de residencia en una clínica de medicina familiar y en una clínica multidisciplinaria especializada en fallo cardiaco para comparar el cumplimiento de las guías de fallo cardiaco ACC/AHA en relación a la medicación y en la reducción de dosis hacia las dosis recomendadas.

Métodos: El estudio fue una revisión retrospectiva de historiales y una recogida de datos que incluyó nombre y dosis de cualquier IECA, betabloqueante, ARA u otra medicación mencionada en las guías.

Resultados: La clínica especializada tuvo presiones sistólicas y fracciones de eyección significativamente más bajas. Se prescribió betabloqueantes significativamente a más pacientes en la clínica especializada ( $98 \%$ vs $80 \%$, p<0.05). Ambos grupos de pacientes tuvieron tasa muy bajas de alcanzar los valores objetivo de dosis de betabloqueantes $(15 \%$ vs $21 \%, \mathrm{p}=0.27)$. Más pacientes en la clínica de medicina familiar alcanzaron las dosis objetivo de IECA (64\% vs $49 \%, \mathrm{p}<0.05)$ y ARA (67\% vs $35 \%, \mathrm{p}<0.05)$. Conclusiones: Este estudio revela que la gran mayoría de pacientes, tanto en un programa de medicina familiar y comunitaria como en una clínica especializada en fallo cardiaco tenían prescritos IECA o ARA y betabloquenates. Sin embargo, alcanzar las dosis objetivo debería continuar a ser una meta para los facultativos.

Palabras clave: Fallo cardiaco sistólico. Farmacoterapia. Cumplimiento de guías. Estados Unidos.

\section{INTRODUCTION}

Heart failure affects more than five million adult Americans with estimated costs of $\$ 37.2$ billion in $2009 .^{1}$ With the number of hospital discharges for heart failure growing and the prevalence of heart failure increasing with age ${ }^{1}$, heart failure management has become increasingly important.

\footnotetext{
*Sarah B. DEHONEY. PharmD, BCPS Emergency Department Clinical Pharmacist. University of Utah, (United States) of Family Medicine. Associate Residency Program Director, Trident/MUSC Family Medicine Residency Charleston, SC (United States).

Jean M. NAPPI. PharmD, FCCP, BCPS, Professor of Clinical Pharmacy and Outcome Sciences. South Carolina College of Pharmacy-MUSC Campus. Professor of Medicine, Medical University of South Carolina. Charleston, SC (United States).
} 
The American College of Cardiology and American Heart Association (ACC/AHA) in collaboration with the American College of Chest Physicians and the International Society for Heart and Lung Transplantation in 2005 developed guidelines to direct the management of chronic systolic heart failure in adults. ${ }^{2}$ The guidelines characterize heart failure as a chronic, progressive disorder which may be classified based on patient risk factors for development of heart failure, degree of structural heart disease, and heart failure symptoms. Patients' symptoms and degree of structural cardiovascular damage can be used to assign a disease stage. The guidelines provide evidence-based recommendations for management of patients in each stage of heart failure to reduce morbidity and mortality from this disease. The Heart Failure Society of America (HFSA) published similar guidelines in $2006 .{ }^{3}$ The HFSA guidelines differ from the ACC/AHA guidelines in a few areas including different evidence-based classification schemes for recommendations, recommendations for systolic heart failure therapy based on New York Heart Association (NYHA) functional classification, and inclusion of recommendations for management of diastolic heart failure. The ACC/AHA guidelines were used for this study because of the heart failure staging system, which does not rely on NYHA functional classification, and the focus on systolic heart failure.

Angiotensin converting enzyme inhibitors (ACEI) and beta-blockers are recommended for patients with reduced left ventricular ejection fraction (LVEF) and current or prior symptoms of heart failure, unless contraindications exist. ${ }^{2}$ Both ACEI and betablockers are recommended for all patients with a recent or remote history of myocardial infarction (MI), regardless of ejection fraction or heart failure symptoms. Angiotensin receptor blockers (ARBs) may be utilized in patients unable to tolerate ACEI. Diuretics are indicated for the management of fluid retention. Aldosterone antagonists may be used in appropriate patients with relatively severe heart failure symptoms and recent decompensation or left ventricular dysfunction early after $\mathrm{MI}$ to reduce mortality. Digoxin may be utilized in later stages of heart failure to reduce heart failure symptoms and hospitalizations due to heart failure. The combination of hydralazine and a nitrate is recommended for patients, particularly African American patients, in the later stages of heart failure with persistent heart failure symptoms despite ACEI and beta-blocker therapy or in those patients who cannot tolerate an ACEI or ARB. The dose of ACEI, beta-blocker, and ARB therapy for heart failure management is an important consideration discussed in the guidelines. It is suggested that titration of these agents should occur with the goal of achieving target doses which were used in controlled trials where benefits including reduced hospitalizations, symptoms, and mortality were demonstrated.

Studies suggest that heart failure management provided by, at least in part, heart failure specialty practitioners improves the likelihood patients will experience better outcomes compared with patients receiving heart failure management by general practitioners alone. ${ }^{4,5}$ Addition of a clinical pharmacist to heart failure management has also been shown to improve patient outcomes compared with patients not receiving any pharmacist interventions. ${ }^{6}$

A quality review of the heart failure medical therapy for two heart failure patient populations was conducted. This study was designed to compare two local ambulatory clinics providing heart failure management, a community family medicine residency program clinic and a multidisciplinary heart failure specialty clinic. In both clinics, pharmacists are members of the heart failure care team, providing patient care and provider education. The primary study objective included comparing adherence to chronic systolic heart failure guidelines ${ }^{2}$, with regard to medications and in titrating to recommended target doses. The secondary objective involved comparing the number of hospital admissions during the study period between the two clinic patient populations. The authors hypothesized that patients attending a heart failure specialty clinic would more often be prescribed medications at target doses recommended by chronic systolic heart failure guidelines when compared with patients attending a community family medicine residency program clinic for heart failure management.

\section{METHODS}

The study was a retrospective chart review of a single study visit for patients receiving heart failure management by either a multidisciplinary heart failure specialty clinic or a community family medicine residency program clinic. Specialty clinic patients were seen by a specialist practitioner, a board-certified cardiologist, whose practice is limited to heart failure and heart transplantation. The family medicine residency program clinic consisted of thirty resident and four attending physicians. Residents spend one to five half-days per week caring for continuity patients, with each resident being precepted by an attending family physician. The family medicine clinic includes an in-house laboratory, a treatment room for management of stable patients, and is located adjacent to the community hospital where patients are admitted for inpatient care.

Family medicine clinic patients were identified through billing codes for office visits for heart failure. Specialty clinic patients were identified by screening the clinic patient roster. All patients were greater than 18 years of age. Exclusion criteria included diastolic heart failure, defined as left ventricular ejection fraction (LVEF) greater than or equal to $50 \%$, hospitalization for heart failure in two months preceding study visit, pregnancy, or no clinic visit in 12 months prior to start of the study period. The most recent clinic visit during the study period (September 2006 to December 2007) was used as the study visit.

A data collection sheet was used to standardize data collection during chart review. Data were 
collected from medical records by two PGY-2 pharmacy residents who had experience in either the specialty or family medicine resident's clinic and data were collected for the site with which the pharmacy resident had experience. A sample of the data extractions were reviewed by two clinical pharmacy specialist faculty members. Data collected included demographic information, date of study visit, name and dose of any ACEI, betablocker, ARB, diuretic, or aldosterone antagonist therapy, and use of digoxin, hydralazine, nitrates, aspirin, or warfarin. Target doses of ACEI, betablockers, and ARBs were determined using published guidelines or available literature if necessary. ${ }^{2,7-11}$ Patient adherence to the pharmacological regimen was not evaluated since the study involved review of medication regimens at a single clinic visit. Use of medications which should generally be avoided in systolic heart failure (such as diltiazem, verapamil, and thiazolidinediones) was also recorded. The most recent LVEF, systolic blood pressure, heart rate, blood urea nitrogen (BUN), and serum creatinine (SCr) were recorded in order to assess the severity of heart failure in the two patient populations, since abnormalities in these parameters have been associated with worse disease prognosis. ${ }^{2}$ NYHA functional class was not routinely evaluated by both clinics so this parameter was not included in analysis. The number of allcause hospital admissions through March 2008 was obtained using the electronic medical record for the specialty clinic patients and billing records for family medicine clinic patients.

Comparison of continuous data including age, weight, systolic blood pressure, heart rate, BUN, SCr, LVEF, and number of hospital admissions was performed using the student's T-test. Comparison of nominal data including sex, race, and prescribing of medications and target doses was performed using the chi-squared test. The study was approved by the institutional review board. significantly older compared with the specialty clinic population (mean age 65 yrs vs 50 yrs, p<0.05). The specialty clinic population had significantly more African American patients compared with the family medicine clinic population $(74 \%$ vs $54 \%$, p<0.05).

The mean heart rate, $\mathrm{BUN}$, and $\mathrm{SCr}$ were not significantly different between the specialty and family medicine clinic populations. The specialty clinic population had a significantly lower mean systolic blood pressure $(114 ; \mathrm{SD}=21 \mathrm{mmHg}$ vs 133 $\mathrm{SD}=30 \mathrm{mmHg}, \quad \mathrm{<}<0.05$ ) and mean left ventricular ejection fraction (27 SD=9\% vs $34 \mathrm{SD}=9 \%, \mathrm{p}<0.05)$.

There was no significant difference in the proportion of patients who were prescribed ACEI and ARBs in the specialty and community family medicine residency program clinic populations $(77 \%$ vs $68 \%$, $p=0.15)$ and $(21 \%$ vs $15 \%, p=0.27)$, respectively. Nine patients (two patients in the specialty clinic population and seven patients in the community clinic population) were not prescribed ACEI or ARBS due to hypotension, angioedema, elevated SCr, continuous inotrope infusions, or for unknown reasons. More patients in the community family medicine residency program clinic population reached target doses of ACEI (64\% vs $49 \%$, $p<0.05)$ and ARBs $(67 \%$ vs $35 \%, p<0.05)$ compared with the specialty clinic population. Significantly more patients were prescribed beta-blockers in the specialty clinic compared with the family medicine clinic population $(98 \%$ vs $80 \%, p<0.05)$. However, both patient populations had very low rates of reaching target beta-blocker doses $(15 \%$ vs $21 \%$, $p=0.27$ ). Significantly more patients attending the specialty clinic were prescribed diuretic therapy compared with the community family medicine residency program clinic ( $93 \%$ vs $66 \%, p<0.05)$.

Other medications which are utilized to treat persistent or refractory heart failure symptoms were prescribed in a higher proportion of patients in the

\begin{tabular}{|c|c|c|c|}
\hline Characteristic & Specialty $(\mathrm{N}=111)$ & Community $(\mathrm{N}=41)$ & P-value \\
\hline Mean age (yrs) & $50(21-85)$ & $65(37-94)$ & $<0.05$ \\
\hline Mean weight $(\mathrm{kg})$ & $96(41-205)$ & $90(44-166)$ & 0.32 \\
\hline$\%$ Male & $56 \%$ & $54 \%$ & 0.78 \\
\hline Race & $\begin{array}{c}74 \% \text { African American } \\
26 \% \text { Caucasian } \\
<1 \% \text { Asian }\end{array}$ & $\begin{array}{c}54 \% \text { African American } \\
44 \% \text { Caucasian } \\
2 \% \text { Other } \\
\end{array}$ & $\begin{array}{l}<0.05 \\
<0.05 \\
\text { NC }\end{array}$ \\
\hline Mean systolic BP (mmHg) & $114(78-185)$ & $133(92-200)$ & $<0.05$ \\
\hline Mean heart rate $(\mathrm{bpm})$ & $78(50-123)$ & $74(49-104)$ & 0.11 \\
\hline $\mathrm{BUN}(\mathrm{mg} / \mathrm{dL})$ & $24(6-95)$ & $22(7-57)$ & 0.44 \\
\hline Serum creatinine & $1.5(0.7-7.4)$ & $1.5(0.5-5.8)$ & 0.84 \\
\hline LVEF (\%) & $27(13-48)$ & $34(15-48)$ & $<0.05$ \\
\hline
\end{tabular}

\section{RESULTS}

There were 152 patients that met inclusion criteria, 111 patients attended the heart failure specialty clinic and 41 patients attended the community family medicine residency program clinic. There were no significant differences between the clinic patient populations with regard to gender or mean body weight as seen in Table 1 . The family medicine residency program clinic population was specialty clinic compared with the community family medicine residency program clinic including digoxin $(52 \%$ vs $17 \%, p<0.05)$, aldosterone antagonists ( $70 \%$ vs $29 \%, \mathrm{p}<0.05)$, nitrates $(35 \%$ vs $22 \%$, $p<0.05)$ except for hydralazine $(22 \%$ vs $15 \%$, $p=0.20$ ) which was not significantly different as depicted in Figure 1. Eleven patients were noted to be prescribed the combination isosorbide dinitrate $20 \mathrm{mg} /$ hydralazine $37.5 \mathrm{mg}$ (BiDil囚) of which ten 
patients were African American and one was Caucasian. Four patients treated at the specialty clinic were receiving continuous inotrope infusions, two patients on dobutamine and two patients on milrinone therapy.

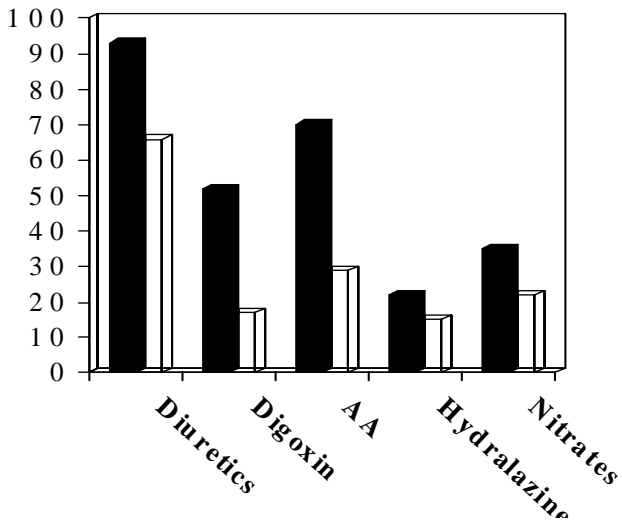

Figure 1. Comparison of the percentage of patients receiving additional medication classes for heart failure treatment between the two clinic patient populations ( $A A=A l d o s t e r o n e ~ a n t a g o n i s t)$. the black bar is Specialty Clinic patients and the white bar is Fam Medicine Clinic patients. For diuretics, digoxin, aldosterone antagonist, and nitrates $\mathrm{p}<0.05$ verapamil were not prescribed for any patients evaluated in this study. One patient in the community family medicine residency program clinic population was prescribed the thiazolidinedione, pioglitazone.

The specialty clinic patient population had a significantly higher mean number of hospital admissions per patient during the study period (1.2 vs $0.6, p<0.05)$.

\section{DISCUSSION}

Previous studies have shown significant reductions in mortality when heart failure management involves cardiology specialists ${ }^{4,5}$ and multidisciplinary teams. ${ }^{12}$ Pharmacist involvement in heart failure management has also been associated with significantly reduced healthcare utilization. 6.13

Rather than focusing on differences in patient outcome variables, the current study aimed to assess the quality of heart failure management using adherence to chronic systolic heart failure guideline medication and dosing recommendations as a means for comparison. The hypothesis $(\mathrm{H} 1)$ for this study assumed patients attending a heart failure specialty clinic would more often be prescribed medications and achieve target doses

\begin{tabular}{|c|c|c|c|c|}
\hline & $\begin{array}{c}\text { Specialty Clinic } \\
\mathrm{N}=111 \\
\text { Number of patients } \\
(\%)\end{array}$ & $\begin{array}{l}\text { Community Clinic } \\
\mathrm{N}=41 \\
\text { Number of patients } \\
(\%)\end{array}$ & $\begin{array}{c}\text { Specialty Clinic } \\
\mathrm{N}=111 \\
\text { Median Daily Dose in } \\
\text { mg (range) }\end{array}$ & $\begin{array}{l}\text { Community Clinic } \\
\qquad \mathrm{N}=41 \\
\text { Median Daily Dose } \\
\text { in } \mathrm{mg} \text { (range) }\end{array}$ \\
\hline Received ACEI or ARB & $109(98.1)$ & $34(82.9)$ & & \\
\hline Lisinopril & $35(31.5)$ & $20(48.8)$ & $20(2.5-80)$ & $20(2.5-40)$ \\
\hline Enalapril & $29(26.1)$ & $2(4.9)$ & $10(2.5-40)$ & $25(10-40)$ \\
\hline Quinapril & $3(2.7)$ & 0 & $20(5-40)$ & 0 \\
\hline Ramipril & $5(4.5)$ & $1(2.4)$ & $10(5-10)$ & 20 \\
\hline Trandolapril & $1(0.9)$ & 0 & 4 & 0 \\
\hline Captopril & $1(0.9)$ & 0 & 75 & 0 \\
\hline Benazepril & $12(10.8)$ & $5(12.2)$ & $17.5(5-80)$ & $40(20-40)$ \\
\hline Valsartan & $13(11.7)$ & $1(2.4)$ & $160(20-160)$ & 80 \\
\hline Losartan & $10(9)$ & $4(9.8)$ & $50(25-100)$ & $50(25-100)$ \\
\hline Irbesartan & 0 & $1(2.4)$ & 0 & 300 \\
\hline Received Beta Blocker & $108(98.1)$ & $33(80.4)$ & & \\
\hline Metoprolol succinate & $24(21.6)$ & $13(31.7)$ & $62.5(12.5-200)$ & $100(25-200)$ \\
\hline Metoprolol tartrate & $8(7.2)$ & $3(7.3)$ & $100(50-125)$ & $50(50-100)$ \\
\hline Carvedilol & $76(68.4)$ & $15(36.6)$ & $37.5(2.5-100)$ & $12.5(3.125-50)$ \\
\hline Atenolol & 0 & $1(2.4)$ & 0 & 25 \\
\hline Sotalol & $1(0.9)$ & $1(2.4)$ & 240 & 360 \\
\hline
\end{tabular}

The use of aspirin and warfarin was also evaluated in the two clinic populations. Significantly fewer specialty clinic patients were prescribed aspirin therapy compared with the community family medicine residency program clinic $(58 \%$ vs $78 \%$, $\mathrm{p}<0.05)$. However, significantly more specialty clinic patients were on warfarin therapy compared with the family medicine patients ( $44 \%$ vs $10 \%, p<0.05$ ).

Certain medications including diltiazem, verapamil, and thiazolidinediones should generally be avoided in patients with chronic systolic heart failure. Diltiazem and recommended in the ACC/AHA heart failure guidelines when compared with patients attending a community family medicine residency program clinic for heart failure management. The study size was small, 152 patients, but represented the entire patient population of the two clinics. Despite differences in age and ethnicity between the two patient populations, the vast majority of patients were prescribed standard therapy consisting of ACEI or ARB and beta-blocker therapy. A significant difference did exist in that more patients in the specialty clinic population were prescribed betablockers. 
The achievement of target doses of standard therapy was also analyzed and expected to be higher in the specialty clinic population, but this was not found to be true in the study results. Significantly more patients in the community family medicine residency program clinic reached target doses of ACEI and ARBs. However, very few patients in either clinic population achieved target doses of beta-blockers which is similar to the results of a retrospective analysis conducted by Gupta and colleagues where the average dose of betablockers used was $52 \%$ of the target dose. ${ }^{14}$ This may be partially explained by the frequent prescribing of carvedilol as compared with metoprolol succinate as seen in Table 2. Frequent use of carvedilol, with its $\alpha 1$ - and $\beta$-receptor blocking effects, may have limited titration due to hypotension compared with metoprolol succinate with solely $\beta$-receptor blocking effects. Review of the COMET trial data revealed $75 \%$ of patients reached target carvedilol doses ${ }^{15}$ compared with the retrospective evaluation of MERIT-HF data in which approximately $88 \%$ of patients eventually achieved target metoprolol doses. ${ }^{16}$ The retrospective evaluation of MERIT-HF data indicated that bradycardia, hypotension, and worsening heart failure symptoms were causes for delayed titration to the target metoprolol dose, with bradycardia being the most common. ${ }^{16}$ However, prescribing beta-blocker therapy, regardless of dose, should not be underestimated as shown in the MOCHA trial in which carvedilol produced a dose-related improvement in LVEF and reduction in mortality when compared with placebo. ${ }^{17}$

In general, less than $70 \%$ of patients achieved target dose ACEI, ARB, or beta-blocker therapy in either clinic patient population. Possible contributors to low achievement of target doses include lack of titration by the prescriber or difficulty titrating due to adverse effects such as hypotension, bradycardia, or renal impairment. The patient characteristics of the specialty clinic population indicate a younger and primarily African American population with more severe heart failure as indicated by lower mean systolic blood pressure and LVEF. These characteristics may have affected the medications prescribed (i.e., BiDil $\otimes$ ) and response to medications (i.e., ACEI) and ability to titrate to target doses. In addition, four patients in the specialty clinic population required continuous inotrope infusions. These characteristics, in combination with the inherent referral bias associated with a specialty clinic, indicate the patient population had more severe heart failure, which likely had a significant impact on the ability to titrate medications to target doses.

In addition, the specialty clinic patients were more often prescribed additional medication classes recommended by the chronic systolic heart failure guidelines including diuretics, aldosterone antagonists, digoxin, and nitrates, but excluding hydralazine which was prescribed similarly between the two clinic populations. Prescribing additional medication classes was likely due to more severe systolic heart failure symptoms in the specialty clinic population. Utilization of additional medication classes for heart failure management may also have contributed to the significantly lower mean systolic blood pressure of the specialty clinic patients.

The authors believe community family medicine clinic patients may have achieved target dose ACEI and ARBs more often because they had higher systolic blood pressure readings allowing greater titration of doses and these patients were prescribed beta-blockers less often than specialty clinic patients.

More community family medicine residency clinic patients were on aspirin therapy, although the proportion of patients with ischemic versus nonischemic heart failure in each clinic population was not captured in the data collection form. More patients in the specialty clinic patient population were on warfarin therapy but the indication (e.g., atrial fibrillation, deep vein thrombosis/pulmonary embolism) was not evaluated during this study.

A major limitation to this study was the small number of patients, especially in the community family medicine residency program clinic, who met inclusion criteria. An a priori power analysis was not performed, so the number of patients included in this study may have been insufficient to find a difference in the endpoints if they did exist. There is also a limitation involving crossover. At least one patient was seen in both clinics. The retrospective single visit design was also a limitation since the results represent patient characteristics and medication regimens at a single study visit. A study involving multiple study visits might allow for more accurate analysis of the prescribing trends in each clinic patient population.

Other limitations to consider include inaccurate data in the electronic medical record, particularly with regard to medication therapy and hospitalizations. It is possible that patients could have been seen in other facilities and this information may not have been captured in our electronic medical records. The severity of illness between the two clinics was not the same and the number of comorbidities was not assessed, both are factors which may have affected the rate of healthcare utilization between the two clinic populations. Lastly, the community family medicine residency program clinic is a training facility where patients are seen sequentially by residents then faculty members, whereas the specialty clinic is not used as a training site for medical residents. The community family medicine residency program may not represent a typical family medicine practice since the residents are in an academic training program with educational seminars and clinical pharmacist involvement in patient care activities.

\section{CONCLUSIONS}

The results of this study suggest that both types of clinics are following the published heart failure guidelines with regard to prescribing ACEI/ARB and beta-blockers. However, achieving recommended target doses, especially of beta-blockers, appeared to be difficult. In order to maximize the morbidity and mortality benefit of these agents, practitioners 
should titrate to target doses unless adverse effects limit titration.

\section{ACKNOWLEDGEMENTS.}

The authors would like to thank Cary Mountjoy, PharmD, and Patrick Mauldin, PhD for the time and assistance contributed to the study and manuscript.

\section{CONFLICT OF INTEREST}

The authors have no conflicts of interest.

\section{References}

1. American Heart Association. Heart Disease and Stroke Statistics- 2009 Update. Dallas, Texas: American Heart Association; 2009.

2. Hunt SA, Abraham WT, Chin MH, Feldman AM, Francis GS, Ganiats TG, Jessup M, Konstam MA, Mancini DM, Michl K, Oates JA, Rahko PS, Silver MA, Stevenson LW, Yancy CW, Antman EM, Smith SC Jr, Adams CD, Anderson JL, Faxon DP, Fuster V, Halperin JL, Hiratzka LF, Jacobs AK, Nishimura R, Ornato JP, Page RL, Riegel B. ACC/AHA 2005 guideline update for the diagnosis and management of chronic heart failure in the adult: summary article: a report of the American College of Cardiology/American Heart Association Task Force on Practice Guidelines (Writing Committee to Update the 2001 Guidelines for the Evaluation and Management of Heart Failure). Circulation. 2005;112:e154-e235.

3. Adams KF, Lindenfeld J, Arnold JMO, Baker DW, Barnard DH, Baughman KL, Boehmer JP, Deedwania P, Dunbar SB, Elkayam U, Gheorghiade M, Howlett JG, Konstam MA, Kronenberg MW, Massie BM, Mehra MR, Miller AB, Moser DK, Patterson JH, Rodeheffer RJ, Sackner-Bernstein J, Silver MA, Starling RC, Stevenson LW, Wagoner LE. HFSA 2006 Comprehensive Heart Failure Practice Guideline. J Card Fail. 2006;12:e1-122.

4. Indridason OS, Coffman CJ, Oddone EZ. Is specialty care associated with improved survival of patients with congestive heart failure? Am Heart J. 2003;145:300-309.

5. Ezekowitz JA, van Walraven C, McAlister FA, Armstrong PW, Kaul P. Impact of specialist follow-up in outpatients with congestive heart failure. CMAJ. 2005;172(2):189-194.

6. Gattis WA, Hasselblad V, Whellan DJ, O'Connor CM. Reduction in heart failure events by the addition of a clinical pharmacist to the heart failure management team: results of the pharmacist in heart failure assessment recommendation and monitoring (PHARM) study. Arch Intern Med. 1999;159:1939-1945.

7. Nordrehaug JE, Omsjo IH, Vollset SE. A 3-month double-blind cross-over study of the effect of benazepril and hydrochlorothiazide on functional class in symptomatic mild heart failure. J Intern Med. 1992;231:589-584.

8. Colfer HT, Ribner HS, Gradman A, Hughes CV, Kapoor A, Laidlaw JC. Effects of once-daily benazepril therapy on exercise tolerance and manifestations of chronic congestive heart failure. The benazepril heart failure study group. Am J Cardiol. 1992;70:354-358.

9. Tonkon M, Awan N, Niazi I, Hanley P, Baruch L, Wolf RA, Block AJ. A study of the efficacy and safety of irbesartan in combination with conventional therapy, including ace inhibitors, in heart failure. Int J Clin Pract. 2000;54(1):11-18.

10. Hudson M, Humphries K, Tu JV, Behlouli H, Sheppard R, Pilote L. Angiotensin II receptor blockers for the treatment of heart failure: a class effect? Pharmacotherapy. 2007;27(4):526-534.

11. Waagstein F, Bristow MR, Swedberg K, Camerini F, Fowler MB, Silver MA, Gilbert EM, Johnson MR, Goss FG, Hjalmarson A. Beneficial effects of metoprolol in idiopathic dilated cardiomyopathy. Metoprolol in dilated cardiomyopathy (MDC) trial study group. Lancet. 1993;342:1441-1446.

12. McAlister FA, Stewart S, Ferrua S, McMurray JJ. Multidisciplinary strategies for the management of heart failure patients at high risk for admission. J Am Coll Cardiol. 2004;44:810-819.

13. Koshman SL, Charrois TL, Simpson SH, McAlister FA, Tsuyuki RT. Pharmacist care of patients with heart failure: a systematic review of randomized trials. Arch Intern Med. 2008;168(7):687-694.

14. Gupta R, Tang WH, Young JB. Patterns of $\beta$-blocker utilization in patients with chronic heart failure: experience from a specialized outpatient heart failure clinic. Am Heart J. 2004;147:79-83.

15. Poole-Wilson PA, Swedberg K, Cleland JG, Di Lenarda A, Hanrath P, Komajda M, Lubsen J, Lutiger B, Metra M, Remme WJ, Torp-Pedersen C, Scherhag A, Skene A. Comparison of carvedilol and metoprolol on clinical outcomes in patients with chronic heart failure in the carvedilol or metoprolol European trial (COMET): randomized controlled trial. Lancet. 2003;362:7-13.

16. Gottlieb SS, Fisher ML, Kjekshus, Deedwania P, Gullestad L, Vitovec J, Wikstrand J. Tolerability of $\beta$-blocker initiation and titration in the metoprolol CR/XL randomized intervention trial in congestive heart failure (MERIT-HF). Circulation. 2002;105:1182-88.

17. Bristow MR, Gilbert EM, Abraham WT, Adams KF, Fowler MB, Hershberger RE, Kubo SH, Narahara KA, Ingersoll H, Krueger S, Young S, Shusterman N. Carvedilol produces dose-related improvements in left ventricular function and survival in patients with chronic heart failure. Circulation. 1996;94:2807-2816. 